\title{
The Measurement and Influencing Factors of Agricultural Carbon Emissions in China's Western Taiwan Straits Economic Zone
}

\author{
Yihui Chen*(**)(***)† and Minjie Li*** \\ *Anxi College of Tea Science, Fujian Agriculture and Forestry University, Fuzhou 350002, China \\ **Anxi Cooperative Innovation Centre of Modern Agricultural Industrial Park, Quanzhou 362406, China \\ ***School of Economics and Management, Fuzhou University, Fuzhou 350116, China \\ †Corresponding author: Yihui Chen; chenyihui@fafu.edu.cn
}

Nat. Env. \& Poll. Tech. Website: www.neptjournal.com

Received: 01-07-2019

Accepted: 19-09-2019

Key Words:

Agricultural carbon emissions; WTS economic zone; OWA aggregation operator; GTWR

\begin{abstract}
Carbon emissions in agricultural production activities have become an important source of accelerating climate warming. At present, low-carbon agriculture is not only an important means to mitigate climate warming, but also a necessary process of transformation from traditional agriculture to modern agriculture. Therefore, to achieve the sustainable development of agriculture in China's Western Taiwan Straits Economic Zone (WTS Economic Zone), the governments should vigorously promote the upgrading and realize the development of low-carbon agriculture. By adopting the latest emission coefficients and the ordered weighted averaging (OWA) aggregation operator, this paper selected agricultural land use, rice paddies, crop production, livestock manure storage and livestock enteric fermentation as the five carbon emission sources, and measured agricultural carbon emissions in the WTS Economic Zone from 2010 to 2017. Thus, from the time perspective, the average agricultural carbon emissions in the WTS Economic Zone showed a fluctuating downward trend, from 762.64 $\times 10^{3}$ tonnes in 2010 to $710.02 \times 10^{3}$ tonnes in 2017 . From the spatial perspective, total agricultural carbon emissions among regions are quite different. To further clarify the factors affecting agricultural carbon emissions in the WTS Economic Zone, by applying the geographically and temporally weighted regression (GTWR) model, this paper selected the research and development intensity, the added value of agriculture, the proportion of agricultural labour force, the overall level of urbanization, per capita disposable income of rural residents and per capita arable land areas as the influencing factors, and then measured the direction and degree of the influences on agricultural carbon emissions in different temporal-spatial backgrounds. The results showed that the added value of agriculture, the proportion of agricultural labour force and per capita arable land areas had positive influences on agricultural carbon emissions, while the research and development intensity, the overall level of urbanization and per capita disposable income of rural residents had negative impacts. Although agricultural carbon emissions in the WTS Economic Zone have decreased in recent years, further measures can be taken to effectively reduce agricultural carbon emissions, and ultimately promote the development of lowcarbon agriculture according to the results of this study.
\end{abstract}

\section{INTRODUCTION}

Since the 21st century, global warming has attracted widespread attention, and carbon emissions are considered to be the leading cause of global warming, even threatening the survival of mankind. Although carbon emissions are mainly caused by the industrial and the service sector, carbon emissions from the agricultural sector cannot be underestimated. According to the statistics, agricultural activities are responsible for approximate $24 \%$ of total anthropogenic carbon emissions and increasing at a fast speed approximate $1 \%$ per annum (Lamb et al. 2016, Pellerin et al. 2017). That is, agriculture has brought about problems such as energy consumption and environmental pollution while feeding all human beings. As one of the largest agricultural developing countries on earth, China has a vast territory and a wide range of agricultural regions. Since the adoption of reforms and opening-up policy from 1978, China's agriculture has developed rapidly and became an important aspect to promote social progress and economic development. However, carbon emissions from the agricultural sector should not be neglected. It should be noted that the annual average carbon emissions from agriculture in China increased by $3.15 \%$ from 2010 to 2017 , accounting for about $17 \%$ of the total carbon emissions (Nayak et al. 2015, Wang et al. 2014). Thus, carbon emissions in the agricultural sector in China need to be further considered and effectively controlled. To reduce agricultural carbon emission, estimating agricultural carbon emissions reasonably and accurately, and clarifying 
the influencing factors of agricultural carbon are of great significance for formulating reasonable agricultural emission reduction measures.

Fujian is the main part of China's Western Taiwan Straits Economic Zone (WTS Economic Zone). The WTS Economic Zone also includes southwestern Zhejiang, northeastern Guangdong and western Jiangxi. The total land area of the WTS Economic Zone is about $296,800 \mathrm{~km}^{2}$, the vast majority of which are mountainous and hilly landforms. For instance, Fujian has a total land area of $123,800 \mathrm{~km}^{2}$, but the mountainous and hilly areas account for more than $80 \%$ of the total. Furthermore, per capita land and per capita arable land area in Fujian are both less than half of the national per capita. Hence, to promote the agricultural economic development, a large number of chemical fertilizers, pesticides and plastic sheeting were used in the agricultural practice, resulting in large amounts of carbon emissions, which seriously restricted agricultural sustainable development. Moreover, per capita agricultural carbon emissions in the WTS Economic Zone were higher than the national per capita agricultural carbon emissions as early as 2005. Therefore, in the future, while ensuring agricultural production and farmers' incomes, reducing agricultural carbon emissions is a huge challenge for agriculture in the WTS Economic Zone. Based on the above background, this study systematically calculated agricultural carbon emissions of 20 prefecture-level cities in the WTS Economic Zone from 2010 to 2017, analysed their spatial and temporal characteristics, measured the influencing factors based on geographically and temporally weighted regression (GTWR), and then put forward the countermeasures of agricultural carbon emission reduction combining the influencing factors and regional status.

Compared with the existing literature, the innovative work of this research mainly manifests in the following three aspects. First, based on the data of 20 prefecture-level cities in the WTS Economic Zone, this research measured agricultural carbon emissions by adopting the latest emissions coefficients released by Intergovernmental Panel on Climate Change (IPCC) in 2006 and World Resources Institute (WRI) in 2015, to realize the more scientific and accurate calculation of agricultural carbon emissions. Second, in the comprehensive evaluation of agricultural carbon emissions, previous literature often neglected the weight of the specific index in different periods and only treated it equally, which lead to a large deviation in the final results of the evaluation model. Compared with previous researches, this paper used the ordered weighted averaging (OWA) aggregation operator to determine the weights of years. Thus, the weighted average of agricultural carbon emissions combining time weights and annual emission quantity was adopted to evaluate agricul- tural carbon emissions comprehensively. Third, because of the huge disparities in production conditions and resource endowments, the level of agricultural economic development, agricultural structure and agricultural production mode show large differences among cities, which lead to significant differences in agricultural carbon emissions in both temporal and spatial distributions. That is, the traditional spatial econometric models will not meet the research requirements any more. This research employed GTWR to analyse the spatial heterogeneity, direction, and degree of the impact of influencing factors on agricultural carbon emissions. On a whole, this paper remeasured agricultural carbon emissions and used OWA aggregation operator to calculate the time weights. Then, by using the GTWR model, this paper analysed the spatiotemporal heterogeneity of the influences of the research and development intensity, the added value of agriculture, the proportion of agricultural labour force, the overall level of urbanization, per capita disposable income of rural residents and the per capita arable land area on agricultural carbon emissions, aiming to provide a reference for the governments of the WTS Economic Zone and other regions to formulate agricultural emission reduction policies.

\section{PAST STUDIES}

\section{Measurement of Carbon Emissions in the Agricultural Sector}

At present, many existing studies have focused on the evaluation of agricultural carbon emissions. Among them, most studies used the simple summation method and emission coefficients recommended by IPCC Guidelines for National Greenhouse Gas Inventories in 2006 to measure carbon emissions in the agricultural sector (Richards et al. 2016, Tubiello et al. 2013, Peter et al. 2016). For instance, according to the IPCC guidelines, Han et al. (2018) measured the carbon emissions in the agricultural sector in China from 1997 to 2015, Zhang et al. (2019) estimated the agricultural carbon emissions in China's main grain-producing areas during the period from 1996 to 2015, and Tian et al. (2016) estimated carbon emissions from agricultural production in Hunan Province in China during the period from 1995 to 2010. However, the IPCC guidelines neglected soil emissions during the agricultural land-use change in its agricultural inventory (Bell et al. 2014). Besides, carbon emission coefficients released in 2006 is no longer suitable for the current emission situation. That is, different methods applied to estimate carbon emissions may give different results. Therefore, scholars have proposed some novel methods to measure carbon emissions in the agricultural sector. Bell et al. (2014) compared the new approach adopted by the Scottish Government with the IPCC guidelines and national communications. Also, a 
novel solution was proposed whereby local governments can measure their carbon emissions independently (Paweł et al. 2018). Yue et al. (2017) estimated the carbon footprint of a range of 6 livestock and 26 crop products, and significant differences between carbon footprints were found across different management patterns and farm scales.

\section{Influencing Factors of Carbon Emissions in the Agricultural Sector}

Carbon emissions in the agricultural sector are influenced by many factors from different aspects. For instance, $1 \%$ increase in agricultural economic growth will give rise to a proportional increase in agricultural carbon dioxide emission by $17 \%$ (Appiah et al. 2018). The marked changes in the structure of different livestock sectors caused the changes in carbon emission inventories and their spatial distribution (Wei et al. 2017). Besides, agricultural technology (Ismael et al. 2018), land use area per capita (Zhao et al. 2018), agricultural land utilization (Lu et al. 2018), conversion of agricultural fields (Sarauer \& Coleman 2018, West \& Marland 2003), agricultural income (Zafeiriou et al. 2018) and agricultural populations (Cui et al. 2018) all affect agricultural carbon emissions.

There are abundant research results on the methods of investigating the relationship between agricultural carbon emissions and their influencing factors. The autoregressive distributed lag model (Zafeiriou et al. 2018), the multivariate model (Tian et al. 2016, Cui et al. 2018), the Granger causality test (Khan et al. 2018, Zaman et al. 2012) and the vector error correction models (Mourao \& Martinho 2017), the logarithmic mean Divisia index (Xiong et al. 2016a) and the variance decomposition (Ismael et al. 2018) were applied to explore the relationship between agricultural carbon emissions and their influencing factors. In addition, other scholars have applied other novel methods such as the denitrification-decomposition model (Yadav \& Wang 2017) and spatial econometric model (Ye et al. 2016) were adopted to explore the relationship between agricultural carbon emissions and their influencing factors.

\section{MATERIALS AND METHODS}

\section{Study Area}

There are mainly 20 prefecture-level cities in the WTS Economic Zone, including 9 in Fujian, 3 in Zhejiang, 4 in Jiangxi and 4 in Guangdong. On the whole, the WTS Economic Zone is located approximately between the longitude $114^{\circ} \mathrm{E}$ and $121^{\circ} \mathrm{E}$, and between the latitude $22^{\circ} \mathrm{N}$ and $30^{\circ} \mathrm{N}$. Also, the WTS Economic Zone, which borders the Yangtze River Delta in the north and the Pearl River Delta in the south, is an important part of China's coastal economic zone and plays an important role in the layout of China's regional economic development. According to the raw data released in the provincial and municipal statistical yearbooks, the added value of agriculture has reached 421.62 billion Chinese Yuan in 2017, accounting for a proportion of $7.83 \%$ of the regional gross product. Additionally, per capita disposable income of rural residents has reached 11,686 Chinese Yuan, which has been increasing every year since 1990. However, the proportion of workers participated in the agricultural sector in the labour force has reached $27.98 \%$ by 2017 . The increased agricultural growth often comes at the expense of environmental interests in China (Han et al. 2018). That is, at present, in the process of agricultural production in the WTS Economic Zone, which is dominated by pesticides, fertilizers and plastic film, not only high energy consumption and low efficiency are common, but also accompanied by a large amount of carbon emissions, affecting the sustainable development of agriculture. However, there are few researches on carbon emissions in the agricultural sector in the WTS Economic Zone, which leads to some shortcomings in the formulation of agricultural policies to control carbon emissions. The geographical location of the WTS Economic Zone is shown in Fig. 1.

\section{Selection of Measurement Indicators}

Because the sources of agricultural carbon emissions are complex and diverse (Zhang et al. 2019), it is necessary to distinguish the sources effectively when measuring carbon emissions. Carbon emissions from the agricultural sector mainly come from greenhouse gas emissions. That means the measurement of carbon emissions in agriculture is transformed into the measurement of greenhouse gas emissions. Then, through conversion coefficients between greenhouse gases and standard carbon, the agricultural carbon emission can be finally obtained. On the whole, the greenhouse gas emissions mainly consist of three types at present: carbon dioxide $\left(\mathrm{CO}_{2}\right)$, methane $\left(\mathrm{CH}_{4}\right)$ and nitrous oxide $\left(\mathrm{N}_{2} \mathrm{O}\right)$. According to the data released in the IPCC Fifth Assessment Report in 2006, the greenhouse effect caused by 1 tonne of $\mathrm{CO}_{2}$ is approximately equivalent to that produced by 0.2727 tonnes of standard carbon. Similarly, 1 tonne of $\mathrm{CH}_{4}$ approximately emits 6.8182 tonnes of standard carbon and 1 tonne of $\mathrm{N}_{2} \mathrm{O}$ approximately emits 81.2727 tonnes of standard carbon.

In the agriculture, there are four major sources of carbon emissions which can also be considered as the source of greenhouse gas emissions: rice paddies and crop production, agricultural land use, livestock breeding and energy consumption in agricultural production, respectively (Cui 


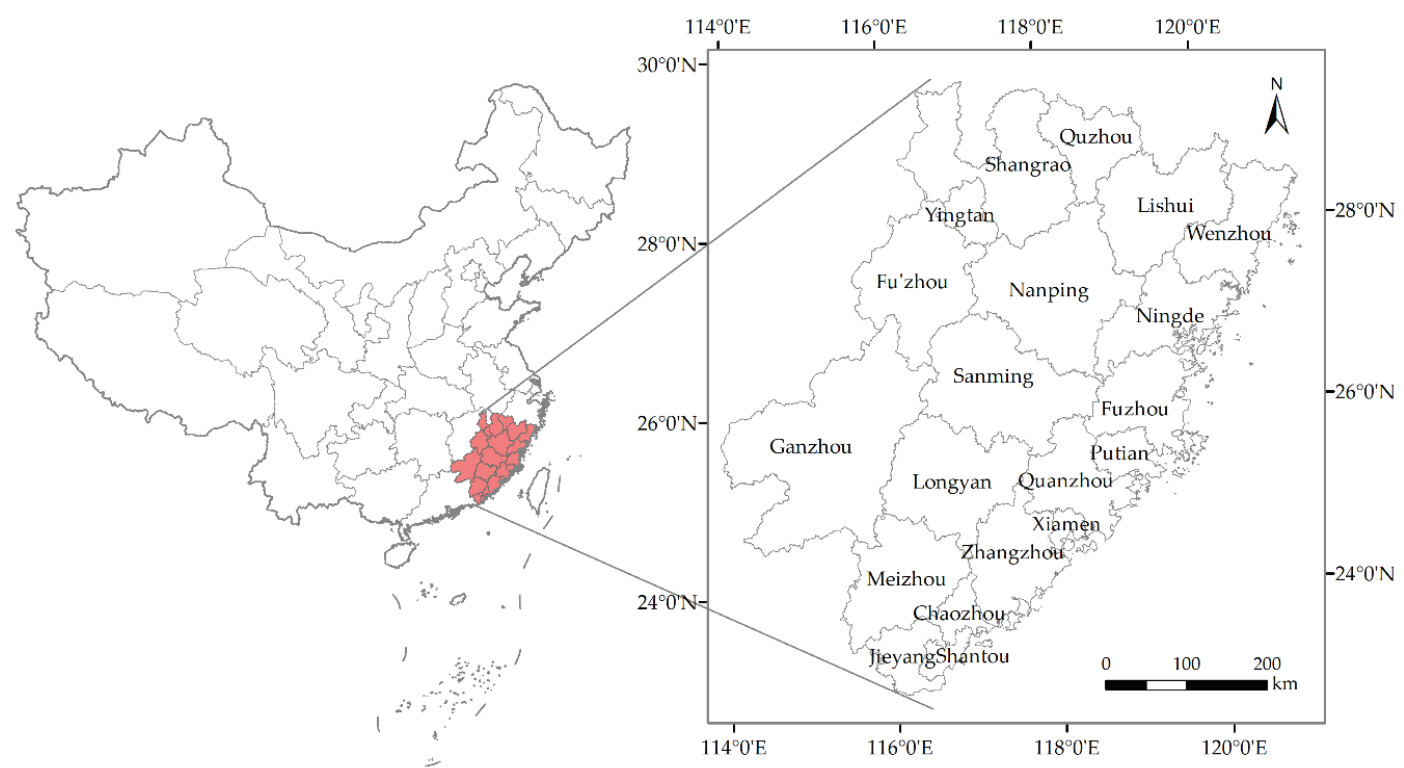

Fig. 1: The geographical location of the WTS Economic Zone.

Table 1: Carbon emission sources and coefficients in agricultural sector.

\begin{tabular}{|c|c|c|c|c|c|}
\hline \multirow{2}{*}{ Sources } & \multirow{2}{*}{ Detailed sources (units) } & \multicolumn{3}{|c|}{ Greenhouse Gases } & \multirow{2}{*}{ References } \\
\hline & & $\mathrm{CO}_{2}$ & $\mathrm{CH}_{4}$ & $\mathrm{~N}_{2} \mathrm{O}$ & \\
\hline \multirow[t]{6}{*}{ agricultural land use } & pesticide (kg/kg) & 18.09 & $\mathrm{n} / \mathrm{a}$ & $\mathrm{n} / \mathrm{a}$ & IPCC \\
\hline & chemical fertilizer $(\mathrm{kg} / \mathrm{kg})$ & 3.28 & $\mathrm{n} / \mathrm{a}$ & $\mathrm{n} / \mathrm{a}$ & IPCC \\
\hline & plastic sheeting (kg/kg) & 19.00 & $\mathrm{n} / \mathrm{a}$ & $\mathrm{n} / \mathrm{a}$ & IPCC \\
\hline & diesel $(\mathrm{kg} / \mathrm{kg})$ & 3.17 & $\mathrm{n} / \mathrm{a}$ & $\mathrm{n} / \mathrm{a}$ & IPCC \\
\hline & tillage $\left(\mathrm{kg} / \mathrm{km}^{2}\right)$ & 1146.31 & $\mathrm{n} / \mathrm{a}$ & $\mathrm{n} / \mathrm{a}$ & IPCC \\
\hline & irrigation (kg/ha) & 977.19 & $\mathrm{n} / \mathrm{a}$ & $\mathrm{n} / \mathrm{a}$ & IPCC \\
\hline \multirow[t]{3}{*}{ rice paddies } & early rice $(\mathrm{kg} / \mathrm{ha})$ & $\mathrm{n} / \mathrm{a}$ & 77.39 & $\mathrm{n} / \mathrm{a}$ & IPCC \\
\hline & late rice $(\mathrm{kg} / \mathrm{ha})$ & $\mathrm{n} / \mathrm{a}$ & 525.95 & $\mathrm{n} / \mathrm{a}$ & IPCC \\
\hline & in-season rice $(\mathrm{kg} / \mathrm{ha})$ & $\mathrm{n} / \mathrm{a}$ & 434.66 & $\mathrm{n} / \mathrm{a}$ & IPCC \\
\hline \multirow[t]{6}{*}{ crop production } & paddy rice (kg/ha) & $\mathrm{n} / \mathrm{a}$ & $\mathrm{n} / \mathrm{a}$ & 0.24 & IPCC \\
\hline & winter wheat (kg/ha) & $\mathrm{n} / \mathrm{a}$ & $\mathrm{n} / \mathrm{a}$ & 2.05 & IPCC \\
\hline & soybean $(\mathrm{kg} / \mathrm{ha})$ & $\mathrm{n} / \mathrm{a}$ & $\mathrm{n} / \mathrm{a}$ & 0.77 & IPCC \\
\hline & vegetable $(\mathrm{kg} / \mathrm{ha})$ & $\mathrm{n} / \mathrm{a}$ & $\mathrm{n} / \mathrm{a}$ & 4.21 & IPCC \\
\hline & maize $(\mathrm{kg} / \mathrm{ha})$ & $\mathrm{n} / \mathrm{a}$ & $\mathrm{n} / \mathrm{a}$ & 2.53 & IPCC \\
\hline & other dry crops (kg/ha) & $\mathrm{n} / \mathrm{a}$ & $\mathrm{n} / \mathrm{a}$ & 0.95 & IPCC \\
\hline \multirow[t]{6}{*}{ manure storage (livestock) } & dairy (kg/head/year) & $\mathrm{n} / \mathrm{a}$ & 8.33 & 2.07 & WRI \\
\hline & non-dairy (kg/head/year) & $\mathrm{n} / \mathrm{a}$ & 3.31 & 0.85 & WRI \\
\hline & goat (kg/head/year) & $\mathrm{n} / \mathrm{a}$ & 0.28 & 0.11 & WRI \\
\hline & pig (kg/head/year) & $\mathrm{n} / \mathrm{a}$ & 5.08 & 0.18 & WRI \\
\hline & poultry (kg/head/year) & $\mathrm{n} / \mathrm{a}$ & 0.02 & 0.01 & WRI \\
\hline & rabbit (kg/head/year) & $\mathrm{n} / \mathrm{a}$ & 0.08 & 0.02 & IPCC \\
\hline \multirow[t]{6}{*}{ enteric fermentation (livestock) } & dairy (kg/head/year) & $\mathrm{n} / \mathrm{a}$ & 89.3 & $\mathrm{n} / \mathrm{a}$ & WRI \\
\hline & non-dairy (kg/head/year) & $\mathrm{n} / \mathrm{a}$ & 67.9 & $\mathrm{n} / \mathrm{a}$ & WRI \\
\hline & goat (kg/head/year) & $\mathrm{n} / \mathrm{a}$ & 9.4 & $\mathrm{n} / \mathrm{a}$ & WRI \\
\hline & pig (kg/head/year) & $\mathrm{n} / \mathrm{a}$ & 1 & $\mathrm{n} / \mathrm{a}$ & WRI \\
\hline & poultry (kg/head/year) & $\mathrm{n} / \mathrm{a}$ & $\mathrm{n} / \mathrm{a}$ & $\mathrm{n} / \mathrm{a}$ & WRI \\
\hline & rabbit (kg/head/year) & $\mathrm{n} / \mathrm{a}$ & 0.25 & $\mathrm{n} / \mathrm{a}$ & IPCC \\
\hline
\end{tabular}

Note: IPCC (Eggleston et al. 2006); WRI (Jiang et al. 2015). 
et al. 2018). However, the first three sources of carbon emissions contribute most to agricultural carbon emissions (Johnson et al.2007). Thus, for the convenience of calculation, the carbon emissions from energy consumption in the agricultural sector are negligible. Therefore, agricultural carbon emissions mainly consist of three parts: (1) the $\mathrm{CO}_{2}$ emissions caused by the agricultural land use; (2) the $\mathrm{CH}_{4}$ emissions produced from rice paddies and livestock breeding; (3) the $\mathrm{N}_{2} \mathrm{O}$ emissions triggered by the crop production and the livestock breeding. Additionally, animals which are not raised and crops which are not planted are negligible. All agricultural carbon emission sources and their corresponding coefficients in the WTS Economic Zone are listed in Table 1.

Based on the existing researches about the carbon emission equation (Xiong et al. 2016a), the total carbon emissions equation in the agricultural sector can be constructed as follows:

$$
E=\sum_{i=1}^{n} E_{i}=\sum_{i=1}^{n} T_{i} \cdot \mu_{i}
$$

Where, E represents the total carbon emissions in the agricultural sector; $E_{\mathrm{i}}$ represents the carbon emission of the specific source $i, \mu_{i}$ represents the carbon emission coefficient of the specific source $i$, and $T_{i}$ denotes the amount of the specific source $\mathrm{i}$. For the convenience of analysis, it is necessary to convert $\mathrm{CO}_{2}, \mathrm{CH}_{4}$ and $\mathrm{N}_{2} \mathrm{O}$ to the standard carbon based on the conversion coefficient mentioned above.

\section{Selection of Influencing Factors}

Research and development intensity (RDI): The investment of research and development (R\&D) contributes to the progress and development of the nation's science and technology. Besides, the measurement of R\&D investment largely depends on the intensity of $R \& D$, that is, the proportion of $\mathrm{R} \& \mathrm{D}$ to GDP. Thus, to control agricultural carbon emissions, it is necessary and effective for the government and relevant departments to increase the R\&D investment intensity (Han et al. 2018, Xiong et al. 2016b). Furthermore, the R\&D investment can effectively promote the progress of agricultural technology with more environmentally friendly, enhance the low-carbon scientific and technological content of agricultural products and services, and then reduce the resulting carbon emissions in the agricultural sector. Therefore, the intensity of research and development is applied and noted as RDI to explorer the influence of science and technology on agricultural carbon emissions. However, the agricultural technological investment may take some time to have a significant impact on agricultural carbon emissions, that is, there is a certain time lag effect. Therefore, this paper calculates the influence of RDI, 1-order-lag RDI and 2-order-lag RDI on agricultural carbon emissions, to determine the optimal time lag for the influence of RDI.

Proportion of agricultural labour force (ALF): As a social development factor, the labour force in the agricultural sector can impact carbon emissions from the crop industry, so as to the agricultural carbon emissions. It is worth noting that with the increase of urbanization, ALF continues to decline, and has reached a very low level, such as $2 \%$ in Jordan in 2014 (Ismael et al. 2018), 1.4\% in the UK in 2010 and less than $1 \%$ in 2016 (Zafeiriou et al. 2018). Because of the absolute demand for natural resources and energies from mankind, there is a strong positive correlation between agricultural population and carbon emissions. Furthermore, the reduction of agricultural labour force shows that the demand for the labour force in agriculture is continually decreasing. Thus, agriculture has begun to improve the production technology through technological progress and other means. Therefore, the surplus labour has migrated from the farmland to other non-agricultural sectors of the national economy.

Added value of agriculture (AVA): The gross output values of farming, forestry, animal husbandry and fishery production were used to measure the agricultural economic growth which was generally proven to promote carbon emissions. Also, the standardized output value of farming, the agricultural added value growth (Xiong et al. 2016b) and per capita gross domestic product (Appiah et al. 2018) were also applied as a proxy of agricultural economic growth. The use of the added value of agriculture as economic growth reflects not only the volume of agricultural economic growth but also the speed of agricultural economic development. That is, the added value of agriculture is a combination of absolute growth and relative growth. Therefore, as an important indicator of agricultural economic growth, the added value of agriculture is applied and noted as AVA to explorer the impact of agricultural economic growth on agricultural carbon emissions.

Overall level of urbanization (OLU): There exists a correlation between the urbanization and the proportion of agricultural labour force. That is, as progress increases in urbanization, a large number of agricultural labour force migrate from agriculture to non-agricultural industries. Therefore, the improvement of urbanization level also means that the quality and agricultural technological skills of agricultural labours continuously improve. Thus, the overall level of urbanization noted as OLU reduces the carbon emissions in the agricultural sector. The urbanization is also increasing land competition between agricultural production and urban expansion. However, Hossain showed that there did not exist a long-term relationship between the level of urbanization and the carbon dioxide emission (Hossain 2011). In a word, most researchers 
approved that the level of urbanization has a decisive influence on agricultural carbon emissions.

Per capita disposable income of rural residents (DIR): There exists bidirectional causality between real income and carbon emissions. As a proxy of economic growth, per capita disposable income of rural residents, marked as DIR, reflects, in particular, the extent of agricultural economic development. The success of economic development in China comes at the cost of over-exploitation of national resources and a tremendous influence on the environment (Tao et al. 2017). Therefore, the mode for giving up the income growth of rural residents to promote carbon emissions reduction in the agricultural sector will not be implemented in China. That is to say, at this stage, the increase of DIR may lead to an increase in carbon emissions. It should be noted that with the increasing demand for green products, farmers with higher incomes can also promote the consumption of low-carbon products through their buying preferences.

Per capita arable land area (ALA): Agricultural land use and land-use change are two of the important factors impacting agricultural carbon emissions. However, it is difficult to estimate the change in agricultural land use in reality. Thus, agricultural land use, especially the per capita arable land area noted as ALA, has become an important factor related to agricultural carbon emissions to be considered. Because agricultural land use is an important source of agricultural carbon emissions, the reduction of the arable land area means that the agricultural land that can generate carbon emissions is also decreasing. In addition, the change of per capita arable land area will also affect the use of chemical fertilizers, pesticides and plastic sheeting, and then affect agricultural carbon emissions. Furthermore, because of the soil erosion and the like (Cui et al. 2018), and the contaminated farmland, carbon emissions from agricultural land use has been changed.

\section{Research Methodologies}

Ordered weighted averaging aggregation operator: The thought of OWA aggregation operator is to determine the corresponding weights according to the decision data itself. Since the introduction of OWA aggregation operator by Yager (1988), researchers have considered and improved the fairness of this weighting method. In this paper, an improved method based on OWA aggregation operator weighting thought proposed by $\mathrm{Xu}$ (2005) was applied to determine the time weights, i.e., a smooth and continuous normal distribution density function method. Thus, the problem of weighting specific indicators in different periods, which was ignored in the previous researches of the comprehensive evaluation of agricultural carbon emissions, is solved. When considering the time weights, the fairness of OWA aggregation operator is more scientific and reasonable than that of the traditional arithmetic average. The specific steps of OWA aggregation operator can be listed as follows:

(1) Assuming that there are $m$ regions and $n$ years; in addition, $E_{i j}$ denotes the total carbon emissions in the agricultural sector in the specific region $i$ in the specific year $j$. Firstly, summing up the specific value of $E_{i j}$ in each year, then the average value can be obtained as follows:

$$
\bar{E}_{j}=\frac{1}{m} \sum_{i=1}^{m} E_{i j}
$$

(2) Then, assuming that the initial weight of total carbon emissions in the specific year is $1 / n$, and the average value and standard deviation of $E_{i j}$ are obtained as follows:

$$
\begin{gathered}
\bar{E}=\frac{1}{n} \sum_{j=1}^{n} \bar{E}_{j} \\
\sigma=\sqrt{\frac{\sum_{j=1}^{n}\left(\bar{E}_{j}-\bar{E}\right)^{2}}{n}}
\end{gathered}
$$

(3) Thirdly, standardizing the total carbon emissions employing the average value and standard deviation mentioned above, and the calculation equation can be obtained as follows:

$$
\beta_{j}=\frac{\bar{E}_{j}-\bar{E}}{\sigma}
$$

(4) Then, using the commonly accepted standard normal distribution density function, then the corresponding values of $\alpha_{j}$ under the different $\beta_{j}$ can be obtained as follows:

$$
\alpha_{j}=\varphi\left(\beta_{j}\right)=\frac{1}{\sqrt{2 \pi}} e^{-\frac{\beta_{j}^{2}}{2}}
$$

(5) Finally, normalizing the obtained value of $\alpha_{j}$ to calculate the time weights by using the formula as follows:

$$
\omega_{j}=\frac{\alpha_{j}}{\sum_{j=1}^{n} \alpha_{j}}
$$

Geographical and temporal weighted regression: The application of traditional linear regression model has a large deviation due to the neglect of spatial factors. Thus, the application of a novel method, the geographically weighted regression model (GWR), solves some of the above problems in the previous researches (Brunsdon et al. 1996). Based on adding the geographical location into the regression coefficient, and the estimation of regression coefficient functions, 
the GWR model can overcome the spatial heterogeneity among geographic units and break through the limitation of the constant coefficient model. However, GWR can only regress the cross-sectional data. That is, GWR model only embeds geographic location parameters into the model, and then forms a model with spatial characteristics, without considering the temporal characteristics of the actual problem ( $\mathrm{Li}$ et al. 2019). Thus, as an extension of the weighted regression model of spatial geography, GTWR, is used to analyse the spatial and temporal chrematistics by incorporating the temporal and spatial characteristics of data into the regression model for analysis. GTWR remains the advantage of a high fitting degree of a local regression model compared with GWR. The general model of GTWR can be constructed as follows ( $\mathrm{Li}$ et al. 2019):

$$
y_{i}=\beta_{0}\left(u_{i}, v_{i}, t_{i}\right)+\sum_{k=1}^{d} \beta_{k}\left(u_{i}, v_{i}, t_{i}\right) x_{i k}+\varepsilon_{i}
$$

Where, $y_{i}$ represents the observations of the total carbon emissions in the agricultural sector, and $x_{i k}$ is the influencing factors at the specific observation point $\left(u_{i}, v_{i}, t_{i}\right) . \beta_{0}$ is the coefficient of the constant. $\left(u_{i}, v_{i}, t_{i}\right)$ represents the longitude and latitude coordinates $u_{i}$ and $v_{i}$, and the observation time point $t_{i}$ of the observation point. $\beta_{k}\left(u_{i}, v_{i}, t_{i}\right)$ denotes the unknown parameter at the specific observation point $\left(u_{i}, v_{i}, t_{i}\right)$, and is the arbitrary function of $\left(u_{i}, v_{i}, t_{i}\right)$. In addition, $\varepsilon_{i}$ is an independent and identically distributed error term and is usually assumed to obey the $N\left(0, \sigma^{2}\right)$ distribution. Besides, the parameters are estimated by the local weighted least squares method. That is, for a given specific observation point, the observation values near the point are given larger weights, while the observation values far from the point are given smaller weights. By minimizing the weighted sum of squares between the observed values and the fitted values, the estimated values of the parameters can be obtained.

\section{RESULTS}

\section{Data Sources}

Various sources of carbon emissions in the agricultural sector are chosen to measure total carbon emissions. Therefore, the carbon emissions from agricultural land use, rice and crop growth process and livestock breeding, as well as their carbon emission coefficients are selected in this study. Among them, the emission coefficients mainly come from the coefficients released by WRI in 2015 and IPCC in 2006. Furthermore, the raw data on the amount of carbon emission sources in the agricultural sector of the provinces from 2010 to 2017 comes from the provincial statistical yearbooks and prefectural-level cities statistical yearbooks. This study does not deal with the original data in any other way. In the end, we obtain the raw data covering 20 prefectural-level cities for 8 years, totalling 160 samples.

\section{Measurement of Agricultural Carbon Emissions}

Time variation of agricultural carbon emissions: The total agricultural carbon emissions calculated based on the carbon emission coefficients are shown in Table 2. As seen in Table 2, the average agricultural carbon emissions in the WTS Economic Zone showed a fluctuating downward trend, from $762.64 \times 10^{3}$ tonnes in 2010 to $710.02 \times 10^{3}$ tonnes in 2017 , with an average annual growth rate of $-0.86 \%$. In addition, the time-variation process of average agricultural carbon emissions showed four-stage characteristics of "risefall-rise-fall". More concretely, agricultural carbon emissions reached the maximum value of $774.98 \times 10^{3}$ tonnes in 2013 and reached the minimum value of $710.02 \times 10^{3}$ tonnes in 2017. Furthermore, agricultural carbon emissions in which has always been in a downward trend from 2010 to 2017 occur in Putian, Wenzhou and Lishui. Agricultural carbon emissions in Fu'zhou and Ganzhou from 2010 to 2017 present a pattern of "N" shape. By contrast, that of in $\mathrm{Fu}$ zhou, Zhangzhou, Nanping, Longyan, Ningde, Quzhou and Shangrao from 2010 to 2017 show an evolutionary trend of the inverse "V" shape, while that of in Xiamen and Quanzhou is "V" shape. In addition, agricultural carbon emissions in Shantou, Jieyang, Chaozhou and Meizhou have a changing pattern of "M" shape, while that of in Sanming and Yingtan have fluctuated. Although some progress has been made during the period in agricultural sustainable development in Fujian, it is still an arduous task at present.

Spatial variation of agricultural carbon emissions: To fully consider the time dimension and ensure that the carbon emissions of different cities can be comprehensively compared, average agricultural carbon emissions calculated based on OWA aggregation operator are listed in the last column of Table 2. That is, these values are calculated by weighting the year first, and then multiplying the carbon emissions of each year and then summing them up. The weights of each year calculated based on OWA aggregation operator are listed in the last row of Table 2. As seen in Table 2, the top five prefecture-level cities of agricultural carbon emissions are Ganzhou, Shangrao, Fu'zhou, Zhangzhou and Nanping, accounting for $51.38 \%$ of the total agricultural carbon emissions in the WTS Economic Zone. By contrast, the last five prefecture-level cities of agricultural carbon emissions are Xiamen, Chaozhou, Putian, Shantou and Meizhou, accounting for only $8.51 \%$ of total agricultural carbon emissions in the WTS Economic Zone. Among them, the average agricultural carbon emission in Ganzhou is $2122.42 \times 10^{3}$ tonnes, 
Table 2: Average agricultural carbon emissions (AACE) in WTS Economic Zone (units: $10^{3}$ tonnes carbon).

\begin{tabular}{|c|c|c|c|c|c|c|c|c|c|}
\hline Cities & 2010 & 2011 & 2012 & 2013 & 2014 & 2015 & 2016 & 2017 & $A A C E$ \\
\hline Chaozhou & 258.85 & 287.51 & 278.66 & 264.75 & 259.94 & 259.62 & 259.67 & 247.07 & 265.91 \\
\hline Fu'zhou & 1497.02 & 1506.76 & 1508.06 & 1492.76 & 1489.49 & 1477.22 & 1502.76 & 1512.78 & 1495.55 \\
\hline Fuzhou & 748.13 & 761.97 & 754.29 & 748.75 & 741.54 & 728.36 & 658.57 & 645.79 & 734.16 \\
\hline Ganzhou & 2074.76 & 2089.12 & 2099.13 & 2129.65 & 2139.46 & 2168.17 & 2144.4 & 2157.54 & 2122.42 \\
\hline Jieyang & 409.29 & 410.64 & 408.86 & 402.16 & 404.92 & 403.14 & 398.48 & 384.35 & 405.13 \\
\hline Lishui & 375.31 & 368.07 & 365.53 & 364 & 345.4 & 337.62 & 318.43 & 310.56 & 352.43 \\
\hline Longyan & 844.88 & 847.72 & 844.65 & 844.59 & 835.18 & 769.2 & 716.58 & 715.98 & 813.5 \\
\hline Meizhou & 337.62 & 340.1 & 347.05 & 346.25 & 343.05 & 350.68 & 348.22 & 336.39 & 344.4 \\
\hline Nanping & 1053.41 & 1065.75 & 1065.76 & 1299.81 & 1088.8 & 1086.94 & 1145.93 & 933.96 & 1099.56 \\
\hline Ningde & 513.09 & 515.18 & 511.42 & 505.39 & 497.19 & 489.83 & 478.49 & 474.64 & 500.88 \\
\hline Putian & 328.08 & 322.95 & 311.75 & 299.66 & 278.62 & 278.43 & 267.48 & 228.45 & 296.14 \\
\hline Quanzhou & 705.85 & 691.92 & 677.6 & 663.43 & 640.98 & 633.5 & 628.09 & 655.61 & 662.42 \\
\hline Quzhou & 552.27 & 574.68 & 578.98 & 553.93 & 479.65 & 443.69 & 422.27 & 414.03 & 509.81 \\
\hline Sanming & 914.94 & 921.81 & 907.74 & 906.69 & 901.55 & 903.8 & 770.21 & 779.9 & 891.01 \\
\hline Shangrao & 1847.69 & 1870.82 & 1880.33 & 1913.7 & 1914.66 & 1919.65 & 1902.57 & 1890.62 & 1892.82 \\
\hline Shantou & 279.48 & 304.96 & 309.37 & 307.77 & 311.55 & 312.75 & 312.92 & 288.5 & 304.85 \\
\hline Wenzhou & 857.63 & 841.71 & 837.06 & 812.57 & 777.19 & 760.31 & 750.61 & 723.04 & 802.49 \\
\hline Xiamen & 87.28 & 86.33 & 86.19 & 82.6 & 66 & 62.09 & 61.48 & 63.72 & 75.04 \\
\hline Yingtan & 391.39 & 388.04 & 390.67 & 395.45 & 394.15 & 396.71 & 397.2 & 393.49 & 393.35 \\
\hline Zhangzhou & 1175.91 & 1181.57 & 1181.36 & 1165.64 & 1155.07 & 1143.35 & 1131.38 & 1043.93 & 1159.13 \\
\hline Average & 762.64 & 768.88 & 767.22 & 774.98 & 753.22 & 746.25 & 730.79 & 710.02 & $\mathrm{n} / \mathrm{a}$ \\
\hline Weights (\%) & 15.67 & 12.76 & 13.60 & 9.56 & 17.97 & 17.38 & 10.75 & 2.31 & $\mathrm{n} / \mathrm{a}$ \\
\hline
\end{tabular}

which is equivalent to 28.28 times of that of in Xiamen, $75.04 \times 10^{3}$ tonnes, which is the smallest. It can be found that the total agricultural carbon emissions among regions are quite different.

Time variation of the structure of agricultural carbon emission sources: The compositions and sources of agricultural carbon emission vary from year to year, as shown in Table 3. Among them, agricultural carbon emissions from rice paddies accounted for the largest proportion, accounting for $42.82 \%$ in 2013. By contrast, agricultural carbon emissions from crop production accounted for the smallest proportion, accounting for only $3.73 \%$ in 2012 . Besides, from the perspective of greenhouse gases, the proportion of $\mathrm{CH}_{4}$ emitted by the five main carbon emission sources was the highest, which can up to $58.94 \%$, and the proportion of $\mathrm{N}_{2} \mathrm{O}$ emitted was the smallest, which can down to $9.32 \%$.

Table 3: The proportion of sources of agricultural carbon emissions in WTS Economic Zone (units: \%).

\begin{tabular}{|lllllllll|}
\hline Sources & 2010 & 2011 & 2012 & 2013 & 2014 & 2015 & 2016 & 2017 \\
\hline Agricultural land use & 31.69 & 32.08 & 32.26 & 31.92 & 33.03 & 33.51 & 34.11 & 33.88 \\
Rice paddies & 42.75 & 42.14 & 41.92 & 42.82 & 41.90 & 42.10 & 41.72 & 42.77 \\
Crop production & 3.76 & 3.79 & 3.73 & 3.77 & 3.93 & 4.02 & 3.92 & 3.80 \\
Livestock: manure storage & 13.04 & 13.39 & 13.50 & 13.04 & 12.61 & 11.97 & 12.22 & 11.84 \\
Livestock: enteric fermentation & 8.76 & 8.60 & 8.59 & 8.45 & 8.53 & 8.40 & 8.03 & 7.71 \\
$\mathrm{CO}_{2}$ & 31.69 & 32.08 & 32.26 & 31.92 & 33.03 & 33.51 & 34.11 & 33.88 \\
$\mathrm{CH}_{4}$ & 58.94 & 58.31 & 58.15 & 58.61 & 57.44 & 57.02 & 56.41 & 56.80 \\
$\mathrm{~N}_{2} \mathrm{O}$ & 9.37 & 9.61 & 9.59 & 9.47 & 9.53 & 9.47 & 9.48 & 9.32 \\
\hline
\end{tabular}




\section{Influencing Factors on Agricultural Carbon Emissions}

The descriptive statistics of all selected variables used in GTWR model, including total carbon emissions and its influencing factors, are shown in Table 4. The standard deviations of some variables reflect that there exist great differences among the cities, that is, the deviation trend is noticeable. For instance, the maximum of ALF is 178.23 times of the minimum, while that of AVA, AACE and RDI reach $35.63,35.27$ and 33.31 times of the minimum respectively. Besides, the concentration trends of DIR, ALF and OLU are more obvious than the dispersion trends. Therefore, the maximum values of DIR and OLU are only 6.02 and 2.40 times of the minimum respectively. It should be noted that to overcome the defect of heteroskedasticity, the original data used in GTWR are applied in the logarithmic form without changing the nature and correlation of original data. Thus, the coefficients of the GTWR model in this paper measure the elasticity of dependent variables to the independent variable, that is, the percentage of the dependent variable change when the independent variable changes by $1 \%$.

This paper applied the GTWR model to measure the direction and degree of factors' influences on agricultural carbon emissions. The descriptive statistics of regression coefficients in the GTWR model are shown in Table 5. As seen in Table 5, the regression coefficient estimation of GTWR model calculated by ArcGIS 10.4.1 shows great heterogeneity of total carbon emissions in the agricultural sector among cities in geographically and temporal attributes. Thus, the GTWR model is suitable for estimating the regression coefficients because of the obvious spatial and temporal non-stationary characteristics of agricultural carbon emissions. Besides, the goodness of fit of the GTWR model is also much better than other models, such as the GWR model and the Ordinary Least Square (OLS). For instance, the value of $\mathrm{R}^{2}$ of the GTWR model is as high as 0.9957 which is very close to 1 , while that of the GWR model and the OLS model only reach 0.9929 and 0.8303 respectively. The estimated regression coefficients reflect the influencing direction and degree of each selected factor on agricultural carbon emissions in different cities in each year. Furthermore, the optimal bandwidth used in GTWR model is determined based on the spatial-temporal weight function of the Gauss function method and the cross-validation. The geographical distribution of regression coefficients of each influencing factor in 2010, 2014 and 2017 are shown in Fig. 2 respectively.

The influence of RDI on agricultural carbon emissions: Considering that the influence of RDI on agricultural carbon emissions may have a time lag period, this paper examines the effects of RDI, 1-order-lag RDI and 2-order-lag RDI on agricultural carbon emissions. The results show that the regression coefficients of RDI and 2-order-lag RDI are not statistically significant, and the regression coefficients of 1-order-leg RDI are significantly negative at the level of $1 \%$.

Table 4: The descriptive statistics of raw data of variables used in the GTWR model.

\begin{tabular}{|lllllllll|}
\hline Variables & Units & Mean & SD & Minimum & $\mathrm{Q}_{1}$ & Median & $\mathrm{Q}_{3}$ \\
\hline AACE & $10^{3}$ tonnes & 751.75 & 544.56 & 61.48 & 345.61 & 603.53 & 930.92 \\
$R D I$ & $\%$ & 1.06 & 0.91 & 0.13 & 0.59 & 0.76 & 1.14 \\
$A L F$ & $\%$ & 30.31 & 11.21 & 0.26 & 27.08 & 32.92 & 38.37 \\
$A V A$ & $10^{8} \mathrm{CNY}$ & 112.73 & 63.23 & 9.69 & 70.34 & 101.60 & 144.23 \\
OLU & $\%$ & 55.96 & 11.09 & 37.20 & 48.45 & 53.55 & 63.15 & 89.17 \\
DIR & $10^{3} \mathrm{CNY}$ & 11.60 & 3.85 & 4.18 & 8.84 & 11.38 & 13.88 \\
$A L A$ & ha / person & 0.04 & 0.02 & 0.01 & 0.03 & 0.04 & 0.06 \\
\hline
\end{tabular}

Table 5: The descriptive statistics of the estimated results of regression coefficients in the GTWR model.

\begin{tabular}{|llllllllll|}
\hline Variables & Mean & Minimum & $\mathrm{Q}_{1}$ & Median & $\mathrm{Q}_{3}$ & Maximum & $\mathrm{SE}$ & $\mathrm{t}$ \\
\hline Intercept & 6.1626 & -37.0190 & -0.5719 & 7.1805 & 12.8774 & 43.8987 & 179.024 & 5.508 & 0.000 \\
LNRDI & -0.4353 & -4.7932 & -0.8848 & -0.2211 & -0.1746 & 4.2874 & 16.208 & -4.297 & 0.000 \\
LNALF & 0.0241 & -0.5754 & -0.0467 & 0.0115 & 0.0791 & 0.6831 & 2.528 & 1.765 & 0.081 \\
LNAVA & 0.7532 & -0.0293 & 0.2959 & 0.7100 & 1.1292 & 2.0646 & 6.608 & 18.249 & 0.000 \\
LNOLU & -0.6123 & -2.7852 & -0.9478 & -0.3873 & -0.1537 & 0.9413 & 9.136 & -10.728 & 0.000 \\
LNDIR & -0.4224 & -5.5209 & -1.3634 & -0.5564 & 0.7064 & 5.4261 & 22.112 & -3.057 & 0.003 \\
LNALA & 0.2268 & -2.5617 & -0.2484 & 0.0888 & 0.9536 & 3.0768 & 13.296 & 2.728 & 0.007 \\
\hline
\end{tabular}




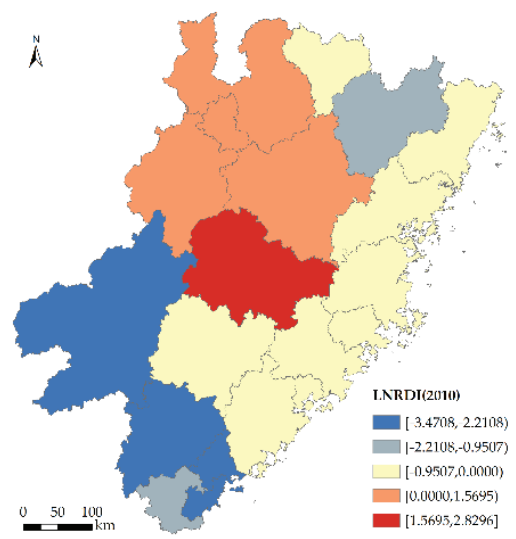

(a) -2010

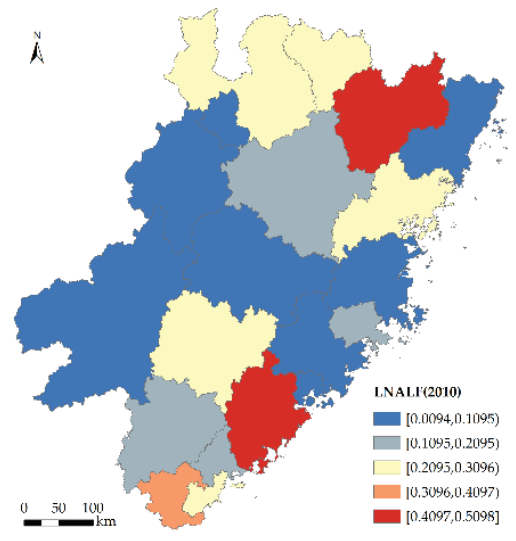

(b) -2010

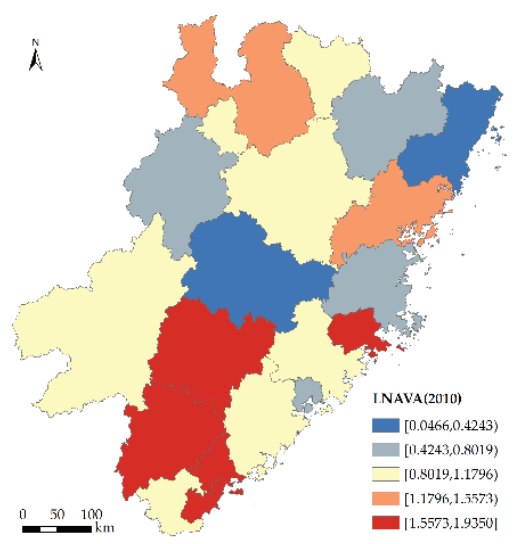

(c) -2010

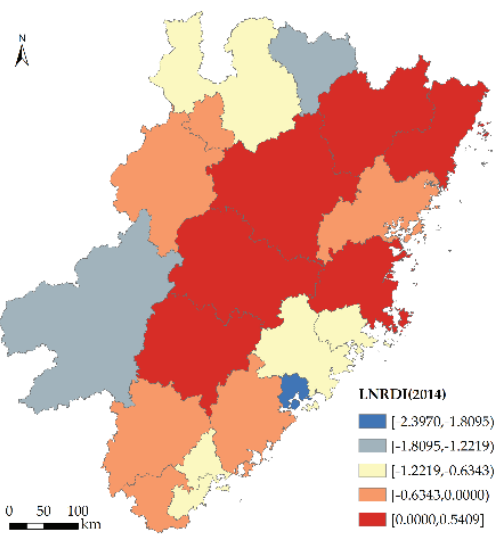

(a) -2014

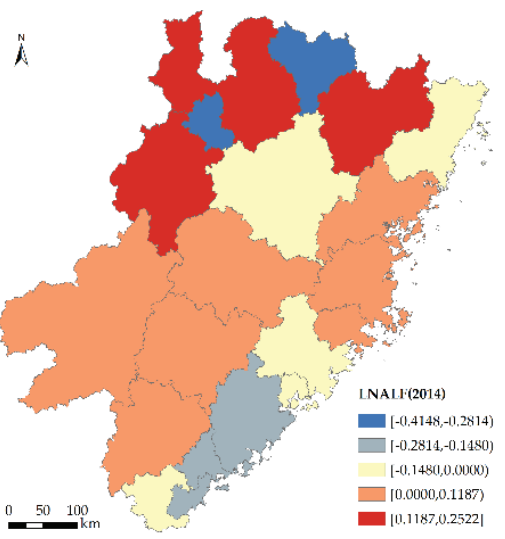

(b) -2014

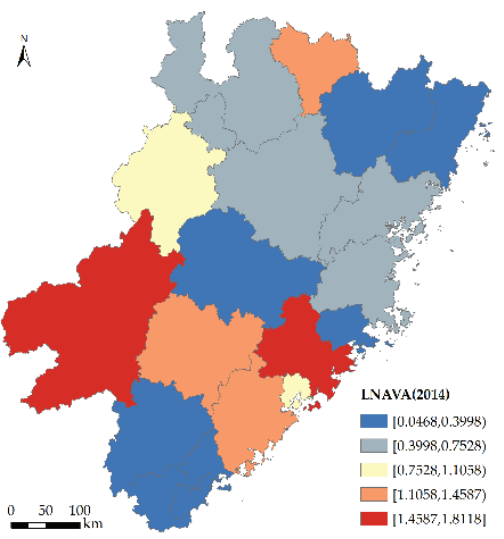

(c)-2014

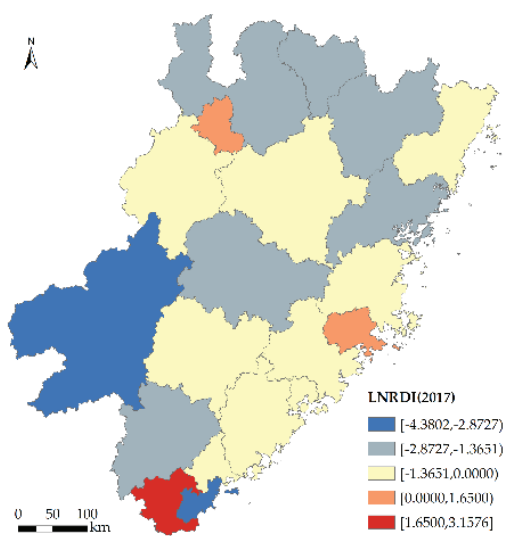

(a) -2017

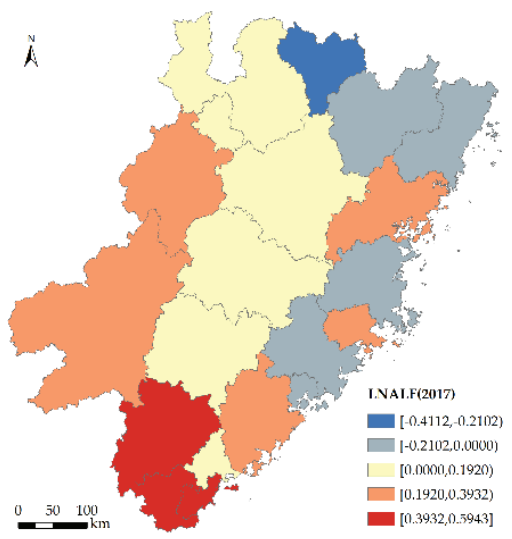

(b) -2017

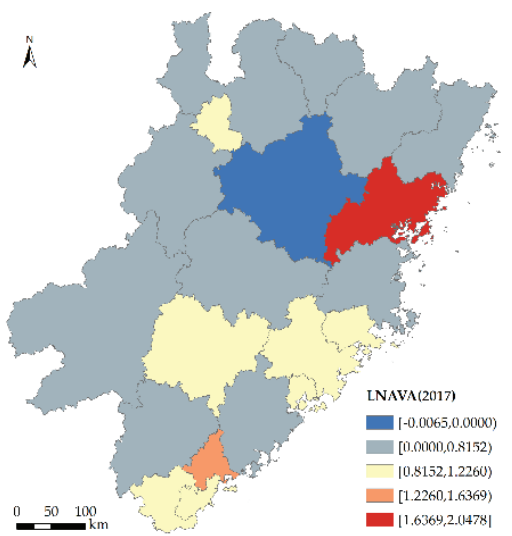

(c)-2017

Fig. cont.... 


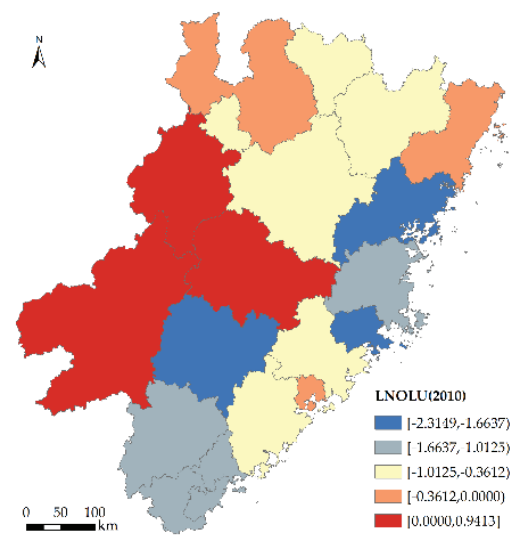

(d)-2010

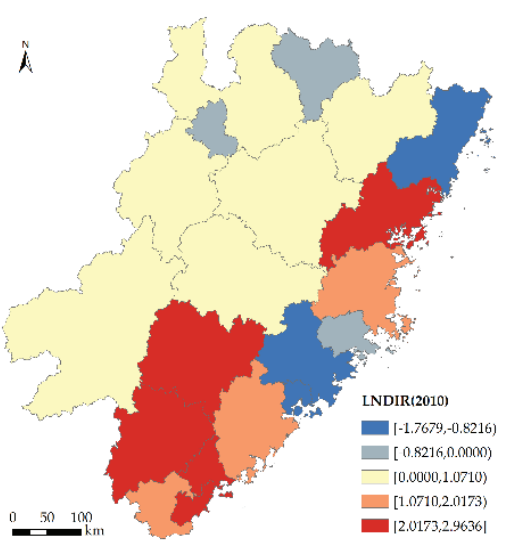

(e)-2010

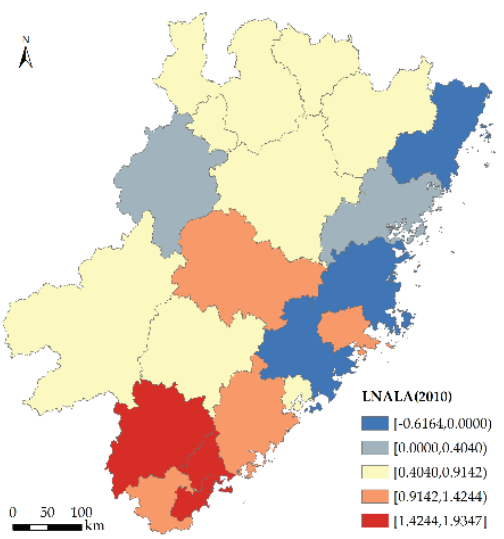

(f) -2010

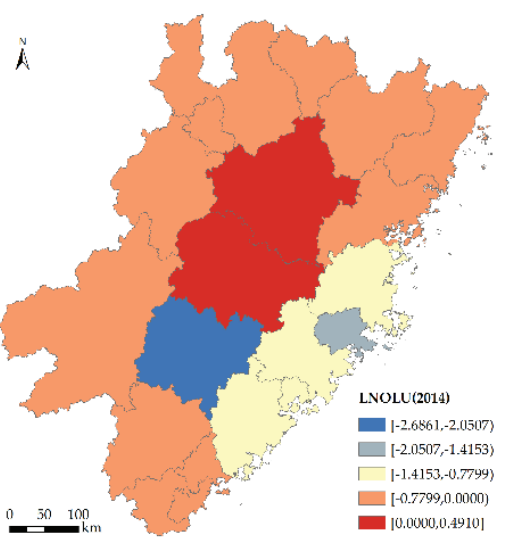

(d)-2014

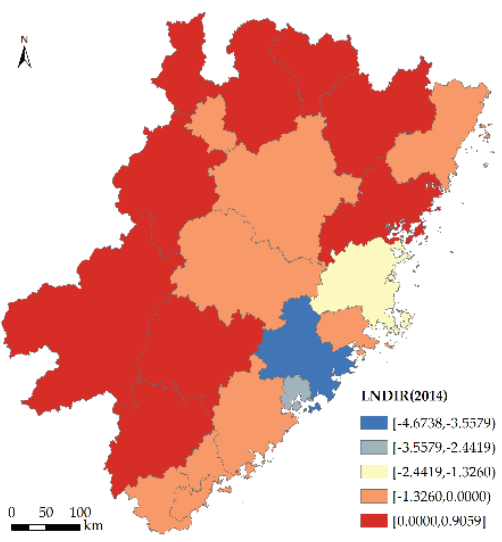

(e)-2014

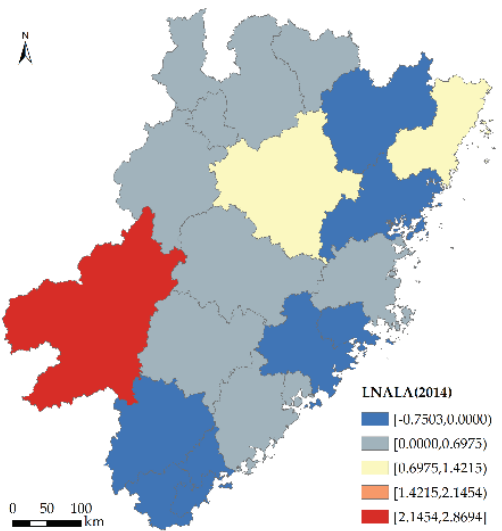

(f)-2014

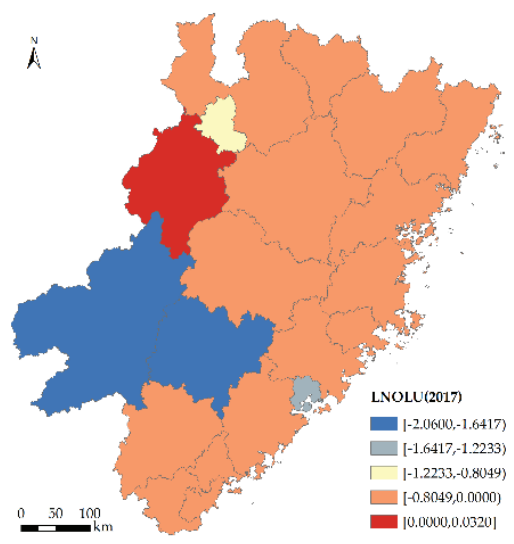

(d)-2017

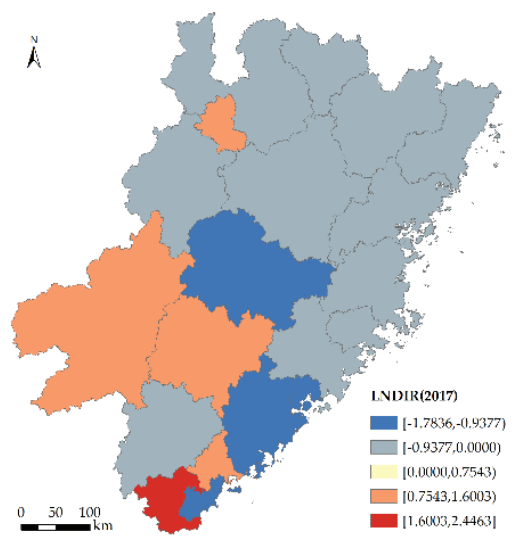

(e)-2017

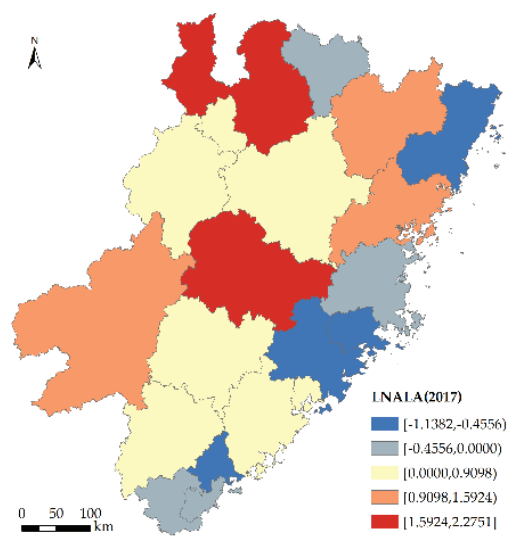

(f)-2017

Fig. 2: Spatial distribution of regression coefficients in 2010, 2014 and 2017. 
Therefore, the RDI selected in this paper is the 1-order-lag RDI. As shown in Table 5, the impact of 1-order-lag RDI on agricultural carbon emissions is mainly negative, which is in good agreement with the expectations. That is, when RDI increase by $1 \%$, the agricultural carbon emissions will decrease by $0.4353 \%$ on average in the opposite direction. Specifically, as shown in Fig. 2(a). from the time perspective, in 2010, the RDI of Fu'zhou, Nanping, Sanming, Shangrao and Yingtan promoted agricultural carbon emissions while that of only in Jieyang, Putian and Yingtan promoted agricultural carbon emissions in 2017. In addition, RDI in other cities in each year has effectively restrained agricultural carbon emissions. Besides, from the spatial perspective, in 2010, RDI of Ganzhou and Chaozhou had great influences on agricultural carbon emissions while that of in 2014 were Quzhou and Ganzhou, and that of in 2017 were Ganzhou and Shantou. The southern cities are relatively advanced in agricultural science and technology compared with those in the northern cities. Thus, governments and enterprises can invest heavily in research and development, and effectively control agricultural carbon emissions through technological improvements.

The influence of ALF on agricultural carbon emissions: The results in Table 5 and Fig. 2(b) showed that ALF had a significant positive impact on agricultural carbon emissions at a significant level of $10 \%$. That is, when ALF increase by $1 \%$, agricultural carbon emissions will increase by $0.0241 \%$ on average in the same direction. In 2010, ALF in all 20 prefecture-level cities promoted agricultural carbon emissions. However, in 2014 and 2017, ALF in some cities, such as Xiamen, Quzhou, Fuzhou and Quanzhou, reduced agricultural carbon emissions. One possible explanation is that in the process of the rapid development of agricultural modernization, these above cities have trained and introduced agricultural technicians and technological professionals, improved the level of agricultural science and technology, and thus reduced agricultural carbon emissions. From the spatial perspective, ALF in cities such as Fu'zhou, Zhangzhou, Yingtan and Jieyang accounts for about $40 \%$ of the total labour force, which has a great impact on agricultural carbon emissions. By contrast, ALF in Xiamen, Fuzhou and Quanzhou only accounts for about $20 \%$ of the total labour force, which has little impact on agricultural carbon emissions. The conclusion may be mainly due to the different orientation and role of different cities in regional development. For instance, some cities mainly develop agriculture to provide agricultural products and services for the surrounding cities while others develop services and manufacturing.

The influence of AVA on agricultural carbon emissions: As seen in Table 5, AVA mainly promotes the average in- creases of carbon emissions in the agricultural sector by $0.7532 \%$ when AVA increases by $1 \%$. As shown in Fig. 2(c), the positive effect of AVA on agricultural carbon emissions in most cities is obvious. One explanation might simply be that the success of the rapid growth of agriculture at the cost of over-exploitation of natural resources and tremendous impact on the environment, especially in Longyan, Quanzhou and Ningde. However, the negative correlation between AVA and total agricultural carbon emissions will become the trend in the future. For instance, AVA showed a negative influence on agricultural carbon emissions in Nanping in 2017. As the main grain producing area in Fujian, Nanping realizes the organic production of agricultural products, the effective control of land use, and the wide application of the Internet of Things in agriculture. Therefore, it is an effective way for governments and enterprises to increase the added value of agriculture to achieve agricultural sustainable development through the improvement and promotion of agricultural technologies.

\section{The influence of OLU on agricultural carbon emissions:}

The urbanization level is often accompanied by a large number of infrastructure investment, the industrial transfer and agglomeration, and the population migration which has an impact on energy consumption and agricultural carbon emissions. As shown in Table 5, the negative impact of OLU on agricultural carbon emissions is significant in most of the cities. That is, when OLU increase by $1 \%$, the agricultural carbon emissions will decrease by $0.6123 \%$ on average in the opposite direction. The positive influence of OLU on agricultural carbon emissions only existed in Fu'zhou, Ganzhou and Sanming in 2010, narrowing to 2 cities including Nanping and Sanming in 2014 and narrowing to 1 city only including Fu'zhou in 2017. As a whole, the overall level of urbanization of southern cities is higher than that of northern cities, that is, the industrial structure, the environmental regulation and the technical level of southern cities of the WTS Economic Zone are better than that of northern cities. Therefore, northern cities should pay more attention to coordinating the relationship between urbanization and agricultural modernization, then realize the synchronous development of agricultural modernization and the transformation of agricultural production organizations.

The influence of DIR on agricultural carbon emissions: On the whole, as shown in Table 5 and Fig. 2(e), DIR has a negative influence on agricultural carbon emissions. When DIR changes by $1 \%$, the average change of agricultural carbon emissions is $0.4224 \%$ in the opposite direction. In 2010, DIR in 6 cities curbed agricultural carbon emissions, expanding to 12 cities in 2014 and 15 cities in 2017. From the perspective of spatial distribution, the regression coeffi- 
cients of DIR in Putian, Quanzhou, Wenzhou and Xiamen were all negative in 2010, 2014 and 2017 while that of in Ganzhou and Longyan were positive. However, other cities have experienced a transformation process of positive-negative influence. The increase of DIR could have promoted the choice of green agricultural products and prompted agricultural producers to reduce chemical fertilizers and pesticides to realize sustainable development. Therefore, the rural residents' rational consumption concept including moderate consumption and green consumption needs to be guided, cultivated and strengthened by governments and enterprises.

The influence of ALA on agricultural carbon emissions: Combining the results of Table 5 and Fig. 2(f), ALA mainly promotes the average increases of carbon emissions in the agricultural sector by $0.2268 \%$ when ALA increases by $1 \%$. From the original data, although the per capita arable land area of cities has little difference, the impact of ALA on agricultural carbon emissions has obvious spatial and temporal differences. On the whole, the positive influence of ALA on agricultural carbon emissions mainly exists in the western cities, especially in Ganzhou and Shangrao. By contrast, Quzhou, Lishui and Wenzhou which located in the northern part became the cities that arable land area exists a negative impact on agricultural carbon emissions. The results further prove that the agricultural development of many cities is at the expense of environmental interests, that is, increasing arable land means increasing agricultural carbon emissions. Therefore, enhancing the capability of deep soil to store the carbons and scientifically changing the way of land cultivation are effective ways to reduce carbon emissions and ultimately achieve sustainable development.

\section{DISCUSSION AND CONCLUSIONS}

This paper remeasured the total agricultural carbon emissions based on the emission coefficients and OWA aggregation operator in the WTS Economic Zone during the period from 2010 to 2017. Moreover, the GTWR model was applied to empirically test the influencing factors on agricultural carbon emissions. By and large, the main findings could be listed as follows. First, from the temporal dimension, although total agricultural carbon emissions in most cities showed a downward trend in the WTS Economic Zone. Second, from the spatial dimension, Fu'zhou, Shangrao and Ganzhou have relatively large agricultural carbon emissions, while Xiamen, Chaozhou and Putian have relatively small agricultural carbon emissions. Finally, the empirical results of the GTWR model indicated that the influences on agricultural carbon emissions had the characteristics of geospatial nonstationarity. Based on the above results, this paper puts forward constructive suggestions on the development of low-carbon agriculture and reduction of agricultural carbon emissions in the WTS Economic Zone.

(1) Low-carbon agriculture is based on science and technology, so to reduce agricultural carbon emissions, it is necessary to strengthen innovative research in agricultural science and technology. Although the total amount of investment in agricultural science and technology in the cities of the WTS Economic Zone has increased, the intensity of investment is still insufficient. For instance, although China's agricultural science and technology investment accounted for $2.14 \%$ of GDP in 2017, Fujian's agricultural science and technology investment accounted for only $0.96 \%$ of GDP. Therefore, in the process of constructing the WTS Economic Zone, the governments need to continuously increase investment in agricultural science and technology, support basic and frontier agricultural scientific research, and accelerate the popularization and application of agricultural technology achievements, e.g., reduce agricultural carbon emissions by promoting intermittent irrigation in paddy fields and improving livestock collection and storage technology. Moreover, organic agriculture may present a positive role in mitigating the environmental burden.

(2) The agricultural industry structure needs to be adjusted and optimized to vigorously develop modern agriculture and ecological agriculture, and finally improve the multifunction of agricultural production. Under the circumstances of ensuring food security, the planting industry is an important breakthrough in reducing agricultural carbon emissions. The interrelated main bodies need to optimize the planting structure, reduce the crop cultivation with large energy consumption and chemical input, and actively adopt new varieties with low carbon, high yield and stress resistance. Besides, combining the advantages of resources in different cities, governments and enterprises should vigorously cultivate characteristic agriculture and take the road of agricultural modernization. Besides, the development of urban agriculture is of great significance to the reduction of agricultural carbon emissions.

(3) The government should effectively control the process of urbanization, improve the basic quality of agricultural personnel, and deepen the concept of green consumption. The governments should strengthen the training of rural residents' skills and environmental awareness of modern agriculture, then train a group of practical talents with both knowledge and quality to meet the needs of modern low-carbon agriculture construction. Furthermore, in the process of urbanization, the governments should increase the investment of infrastructure, and provide necessary conditions for the realization 
of agricultural scale and industrialization. Thus, the governments should correctly handle the nurturing relationship between industry and agriculture, actively implement the strategy of urban-rural integration, and ultimately realize the coordinated development of urbanization and agricultural modernization.

(4) As a regional concept, the WTS Economic Zone aims to highlight the overall regional advantages through resource integration and mutual exchanges and links. Therefore, in the process of developing low-carbon agriculture and reducing agricultural carbon emissions, exchanges and integration are indispensable. For 20 prefecture-level cities in the WTS Economic Zone, agricultural cooperation and linkages can be strengthened in terms of variety, technology and processing. Besides, the WTS Economic Zone can take advantage of the geographical advantages of Taiwan Province, introduce advanced planting technology and new agricultural varieties, learn new agricultural management mode, to effectively reduce agricultural carbon emissions.

\section{ACKNOWLEDGEMENTS}

This research was funded by The Ministry of Agriculture and Rural Affairs: The Construction of Anxi Modern Agricultural Industrial Park (Grant No. KMD18003A) and The Social Science Planning Project of Fujian Province (Grant No. FJ2018C045) in China.

\section{REFERENCES}

Appiah, K., Du, J.G. and Poku, J. 2018. Causal relationship between agricultural production and carbon dioxide emissions in selected emerging economies. Environmental Science and Pollution Research, 25: 24764-24777.

Bell, M.J., Cloy, J.M. and Rees, R.M. 2014. The true extent of agriculture's contribution to national greenhouse gas emissions. Environmental Science \& Policy, 39: 1-12.

Brunsdon, C., Fotheringham, A.S. and Charlton, M.E. 1996. Geographically weighted regression: A method for exploring spatial nonstationarity. Geographical Analysis, 28(4): 281-298.

Cui, H., Zhao, T. and Shi, H. 2018. STIRPAT-based driving factor decomposition analysis of agricultural carbon emissions in Hebei, China. Polish Journal of Environmental Studies, 27(4): 1449-1461.

Eggleston, S., Buendia, L., Miwa, K., Ngara, T. and Tanabe, K. 2006. 2006. IPCC guidelines for national greenhouse gas inventories (Vol. 4). Hayama, Japan: Institute for Global Environmental Strategies.

Han, H.B., Zhong, Z.Q., Guo, Y., Xi, F. and Liu, S.L. 2018. Coupling and decoupling effects of agricultural carbon emissions in China and their driving factors. Environmental Science and Pollution Research, 25: 25280-25293.

Hossain, M.S. 2011. Panel estimation for $\mathrm{CO}_{2}$ emissions, energy consumption, economic growth, trade openness and urbanization of newly industrialized countries. Energy Policy, 39(11): 6991-6999.

Ismael, M., Srouji, F. and Boutabba, M.A. 2018. Agricultural technologies and carbon emissions: Evidence from Jordanian economy. Environmental Science and Pollution Research, 25(11): 10867-10877.
Jiang, X., Fang, W., Zhuang, G., Bai, W., Zhu, S., Lu, L. and Feng, J. 2015. Greenhouse gas accounting tool for Chinese cities (Version 2.0). World Resources Institute.

Johnson, M.F., Franzluebbers, A.J., Weyers, S.L. and Reicosky, D.C. 2007. Agricultural opportunities to mitigate greenhouse gas emissions. Environmental Pollution, 150(1): 107-124.

Khan, M.T.I., Ali, Q. and Ashfaq, M. 2018. The nexus between greenhouse gas emission, electricity production, renewable energy and agriculture in Pakistan. Renewable Energy, 118: 437-451.

Lamb, A., Green, R., Bateman, I., Broadmeadow, M. and Balmford, A. 2016. The potential for land sparing to offset greenhouse gas emissions from agriculture. Nature Climate Change, 6(5): 488-492.

Li, M., Wang, J. and Chen, Y. 2019. Evaluation and influencing factors of sustainable development capability of agriculture in countries along the Belt and Road Route. Sustainability, 11(7): 2004.

Lu, X., Kuang, B., Li, J., Han, J. and Zhang, Z. 2018. Dynamic evolution of regional discrepancies in carbon emissions from agricultural land utilization: Evidence from Chinese provincial data. Sustainability, 10(2): 552.

Mourao, P.R. and Domingues Martinho, Vítor. 2017. Erratum to: Portuguese agriculture and the evolution of greenhouse gas emissions - can vegetables control livestock emissions? Environmental Science and Pollution Research, 24: 16107-16119.

Paweł, Wi niewski and Kistowski, M. 2018. Assessment of greenhouse gas emissions from agricultural sources in order to plan for needs of low carbon economy at local level in Poland. Geografisk Tidsskrift-Danish Journal of Geography, 118(2): 123-136.

Pellerin, S., Bamière, Laure, Angers, D., Béline, Fabrice, Benoit, M. and Butault, J.P. 2017. Identifying cost-competitive greenhouse gas mitigation potential of French agriculture. Environmental Science \& Policy, 77: 130-139.

Peter, C., Fiore, A., Hagemann, U., Nendel, C. and Xiloyannis, C. 2016. Improving the accounting of field emissions in the carbon footprint of agricultural products: A comparison of default IPCC methods with readily available medium-effort modeling approaches. The International Journal of Life Cycle Assessment, 21(6): 791-805.

Richards, M., Metzel, R., Chirinda, N., Ly, P., Nyamadzawo, G. and Duong $\mathrm{Vu}, \mathrm{Q}$. 2016. Limits of agricultural greenhouse gas calculators to predict soil $\mathrm{N}_{2} \mathrm{O}$ and $\mathrm{CH}_{4}$ fluxes in tropical agriculture. Scientific Reports, 6(1).

Sarauer, J.L. and Coleman, M.D. 2018. Converting conventional agriculture to poplar bioenergy crops: Soil greenhouse gas flux. Scandinavian Journal of Forest Research, 33(8): 781-792.

Tao, F., Zhang, H., Hu, J. and Xia, X.H. 2017. Dynamics of green productivity growth for major Chinese urban agglomerations. Applied Energy, 196: 170-179.

Tian, J.X., Yang, H.L., Xiang, P.A., Liu, D.W. and Li, L. 2016. Drivers of agricultural carbon emissions in Hunan province, China. Environmental Earth Sciences, 75(2): 121.

Tubiello, F.N., Salvatore, M., Rossi, S., Ferrara, A., Fitton, N. and Smith, P. 2013. The FAOSTAT database of greenhouse gas emissions from agriculture. Environmental Research Letters, 8(1).

Wang, W., Koslowski, F., Nayak, D.R., Smith, P., Saetnan, E. and Ju, X. 2014. Greenhouse gas mitigation in Chinese agriculture: Distinguishing technical and economic potentials. Global Environmental Change, 26: 53-62.

Wei, S., Bai, Z.H., Chadwick, D., Hou, Y., Qin, W. and Zhao, Z.Q. 2017. Greenhouse gas and ammonia emissions and mitigation options from livestock production in peri-urban agriculture. Journal of Cleaner Production, 178: 515-525.

West, T.O. and Marland, G. 2003. Net carbon flux from agriculture: carbon emissions, carbon sequestration, crop yield, and land-use change. Biogeochemistry, 63(1): 73-83.

Xiong, C., Yang, D. and Huo, J. 2016a. Spatial-temporal characteristics and LMDI-based impact factor decomposition of agricultural carbon 
emissions in Hotan Prefecture, China. Sustainability, 8(3): 262.

Xiong, C., Yang, D., Huo, J. and Zhao, Y. 2016b. The relationship between agricultural carbon emissions and agricultural economic growth and policy recommendations of a low-carbon agriculture economy. Polish Journal of Environmental Studies, 25(5): 2187-2195.

$\mathrm{Xu}, \mathrm{Z}$. 2005. An overview of methods for determining OWA weights: research articles. International Journal of Intelligent Systems, 20(8): 843-865.

Yadav, D. and Wang, J. 2017. Modelling carbon dioxide emissions from agricultural soils in Canada. Environmental Pollution, 230: 1040-1049.

Yager, R.R. 1988. On ordered weighted averaging aggregation operations in multicriteria decision making. IEEE Trans. Systems Man Cybernet, 18(1): 80-87.

Ye, R., Espe, M.B., Linquist, B., Parikh, S.J., Doane, T.A. and Horwath, W.R. 2016. A soil carbon proxy to predict $\mathrm{CH}_{4}$ and $\mathrm{N}_{2} \mathrm{O}$ emissions from rewetted agricultural peatlands. Agriculture, Ecosystems \& Environment, 220: 64-75.
Yue, Q., Xu, X., Hillier, J., Cheng, K. and Pan, G. 2017. Mitigating greenhouse gas emissions in agriculture: From farm production to food consumption. Journal of Cleaner Production, 149: 1011-1019.

Zafeiriou, E., Mallidis, I., Galanopoulos, K. and Arabatzis, G. 2018. Greenhouse gas emissions and economic performance in EU agriculture: An empirical study in a non-linear framework. Sustainability, 10(11): 3837.

Zaman, K., Khan, M.M., Ahmad, M. and Khilji, B.A. 2012. The relationship between agricultural technologies and carbon emissions in Pakistan: Peril and promise. Economic Modelling, 29(5): 1632-1639.

Zhang, L., Pang, J., Chen, X. and Lu Z. 2019. Carbon emissions, energy consumption and economic growth: Evidence from the agricultural sector of China's main grain-producing areas. Science of the Total Environment, 665: 1017-1025.

Zhao, R., Liu, Y., Tian, M., Ding, M., Cao, L., Zhang, Z. and Yao, L. 2018. Impacts of water and land resources exploitation on agricultural carbon emissions: The water-land-energy-carbon nexus. Land Use Policy, 72: 480-492. 